\title{
Brief interventions implementation on alcohol from the European health systems perspective
}

\author{
Joan Colom ${ }^{1}$, Emanuele Scafato ${ }^{2}$, Lidia Segura ${ }^{1}$, Claudia Gandin $^{2}$ and Pierluigi Struzzo ${ }^{3,4}$ * \\ 1 Program on Substance Abuse, Public Health Agency of Catalonia, Barcelona, Spain \\ ${ }^{2}$ Istituto Superiore di Sanità, Rome, Italy \\ ${ }^{3}$ Regional Centre for the training in Primary Care (Ceformed), Monfalcone, Italy \\ ${ }^{4}$ Department of Life Sciences, University of Trieste, Trieste, Italy
}

Edited by:

Hugo López-Pelayo, Fundació Clínic per la Recerca Biomèdica, Spain

\section{Reviewed by:}

Giovanni Martinotti, Università degli Studi Gabriele D'Annunzio, Italy

Luigi Janiri, Università Cattolica del

Sacro Cuore, Italy

\section{${ }^{*}$ Correspondence:}

Pierluigi Struzzo, Department of Life

Sciences, University of Trieste, Via

Weiss 2, Trieste 34128, Italy

e-mail: pstruzzo@gmail.com
Alcohol-related health problems are important public health issues and alcohol remains one of the leading risk factors of chronic health conditions. In addition, only a small proportion of those who need treatment access it, with figures ranging from 1 in 25 to 1 in 7. In this context, screening and brief interventions (SBI) have proven to be effective in reducing alcohol consumption and alcohol-related problems in primary health care $(\mathrm{PHC})$ and are very cost effective, or even cost-saving, in PHC. Even if the widespread implementation of SBI has been prioritized and encouraged by the World Health Organization, in the global alcohol strategy, the evidence on long term and population-level effects is still weak. This review study will summarize the SBI programs implemented by six European countries with different socio-economic contexts. Similar components at health professional level but differences at organizational level, especially on the measures to support clinical practice, incentives, and monitoring systems developed were adopted. In Italy, cost-effectiveness analyses and Internet trials shed new light on limits and facilitators of renewed, evidence-based approaches to better deal with brief intervention in PHC. The majority of the efforts were aimed at overcoming individual barriers and promoting health professionals' involvement. The population screened has been in general too low to be able to detect any population-level effect, with a negative impact on the acceptability of the program to all stakeholders. This paper will present a different point of view based on a strategic broadening of the implemented actions to real inter-sectoriality and a wider holistic approach. Effective alcohol policies should strive for quality provision of health services and the empowerment of the individuals in a health system approach.

Keywords: alcohol, brief interventions, health system, empowerment, resilience

\section{INTRODUCTION AND METHODS}

This is a review study to discuss how screening and brief interventions (SBI) for harmful alcohol use and alcohol dependence can be better embedded in health system (HSys) and implemented effectively. To do so, first the challenges for AUD treatment and the HS responses, as recommended by World Health Organization (WHO), are presented, followed by a review of the existing SBI evidence and the cases of SBI wide implementation and finally some future directions toward the achievement of this objective are proposed. Even if there is still considerable confusion in the literature regarding the SBI evidence, SBI programs have been implemented nation-wide in some countries with some positive results and could be seen as important cornerstones to implement more broaden national policies on alcohol risk reduction. There is, however, a long road ahead. The situation regarding alcohol use is changing dramatically, with the frequent presence of binge drinking in youths, the constant of poly abuse, typically of novel psychoactive substances (1), and the regular report of co-morbid psychiatric disorders (2). The results of the existing experiences urge HSys to move beyond a focus on individual (professional's and patient's) behavior toward implementing policies having into account a wide range of social and environmental interventions, the so-called health promotion, as defined by the $\mathrm{WHO}^{1}$.

The novelty that this review will bring to the reader mainly refers to a point of view that focuses on "what works" and also on broadening future actions with real inter-sectorial strategies encompassing health services (HS) with other sectors of the society and addressing the individual alcohol user with SBI included into a broader, holistic, risk-reduction approach. As alcohol is a complex issue, the general idea is to move from a health service-centered to a broader HSys intervention.

\section{HEALTH SERVICES IN RESPECT TO BRIEF INTERVENTIONS FOR ALCOHOL USE DISORDERS IN EUROPE: THE CHALLENGE OF THE TREATMENT GAP}

According to the WHO, HS, the most visible functions of any HSys, include all services dealing with the diagnosis and treatment of disease or the promotion, maintenance, and restoration of health. In

\footnotetext{
${ }^{1}$ Health promotion is the process of enabling people to increase control over, and to improve, their health. It moves beyond a focus on individual behavior toward a wide range of social and environmental interventions (WHO definition).
} 
this sense, WHO have stressed that HS for AUD have the following objectives:

- provide prevention and treatment interventions to individuals and families at risk of, or affected by, AUDs and associated conditions;

- inform societies about the public health and social consequences of hazardous and harmful alcohol consumption (HHAC);

- support communities in their efforts to reduce HHAC;

- advocate effective societal responses.

Despite the efforts made by WHO and all the countries to improve AUD treatment, evidence still shows that the so-called treatment gap is huge. From one side harmful alcohol users are still socially stigmatized and do not seek treatment and from another access to effective alcohol treatment services is limited in many European countries. It has been estimated that only 1 in 20 of those with HHAC are actually identified and offered brief advice by a primary care service provider. Similarly, $<1$ in 20 with a diagnosis of alcohol dependence has actually seen a specialist for treatment (3).

Taking into account this reality and the ambitious AUD treatment objectives, it is clear that a cultural change in the way alcohol problems are seen is needed. As a consequence of that we need to mobilize and involve of a broad range of players inside and outside the health sector, sufficiently strengthened and properly funded in a way that is commensurate with the magnitude of the public health problems caused by HHAC. This means broadening the horizon to a much wider HSys approach ${ }^{2}$ (3).

The provision of early intervention and treatment services is a key part of any comprehensive policy framework to reduce alcohol harm (4). The WHO "Global Strategy to Reduce the Harmful Use of Alcohol," 2010, lists National HSys' response as one of its key priority policy areas (5): (1) leadership, awareness, and commitment; (2) HS's response; (3) community action; (4) drink-driving policies and countermeasures; (5) availability of alcohol; (6) marketing of alcoholic beverages; (7) pricing policies; (8) reducing the negative consequences of drinking and alcohol intoxication; (9) reducing the public health impact of illicit alcohol and informally produced alcohol; and (10) monitoring and surveillance.

The portfolio of policy options and interventions recommended by the WHO for HSys's response area include

(a) increasing capacity of health and social welfare systems to deliver prevention, treatment and care for AUDs, including support and treatment for affected families, and support for mutual help or self-help activities and programs;

(b) supporting initiatives for SBI for HHAC at primary health care (PHC) and other settings including initiatives among pregnant women and women of child-bearing age;

(c) improving capacity for prevention of, identification of, and interventions for individuals and families living with fetal alcohol syndrome and a spectrum of associated disorders;

${ }^{2} \mathrm{~A}$ health system is the sum total of all the organizations, institutions, and resources whose primary purpose is to improve health. (d) development and effective coordination of integrated and/or linked prevention, treatment, and care strategies and services for AUDs, including drug-use disorders, depression, suicides, HIV/AIDS, and tuberculosis;

(e) securing universal access to health, enhancing availability, accessibility, and affordability of treatment services for groups of low socio-economic status;

(f) establishing and maintaining a system of registration and monitoring of alcohol-attributable morbidity and mortality, reported on a regular basis;

(g) provision of culturally sensitive health and social services as appropriate (5).

In respect to SBI for alcohol-related problems, HS are central to tackling harm at individual level among those with AUDs and other conditions caused by HHAC. The outcome expected by the WHO action plan to reduce HHAC 2012-2020 is a progressive reduction in the gap between the number of people who would benefit from alcohol consumption advice to reduce or prevent harm, engagement in social rehabilitation programs or treatment for AUDs and the number who actually receive such advice or treatment to be monitored (using as indicators the proportion of the adult population with HHAC, and of the population with HHAC who have received therapy and advice from a primary care provider to reduce their alcohol consumption) (3).

The health sector and the social welfare, education, and workplace sectors have real opportunities to reap both health gain and financial savings through the widespread implementation of SBI programs that have been shown to reduce ill health and premature death subsequent to HHAC and the implementation of evidence-based treatment programs for AUDs (3).

It is estimated that of the total cost to the NHS from alcohol harm each year, only around $2 \%$ is spent on identifying and treating AUDs. Implementing SBI does not require extensive training and can be delivered in a variety of settings: emergency and hospital care, PHC, schools, job centers and pharmacies, social services, accident, workplace settings, and prisons (6).

There is a strong evidence to support the benefits of widespread implementation of SBI provided by Primary Care and other health or social care professionals while, for alcohol dependent subjects, access to effective treatment services can play a vital role in both recovery from and management of AUDs (6).

According to the WHO, Governments should support SBI programs and referral to specialist services by ensuring that

- clinical guidelines for such interventions are widely available;

- primary care providers receive the training, clinical materials/tools, and advice they need to set up such programs;

- primary care providers are adequately reimbursed for the interventions.

Furthermore, primary care providers should be encouraged to undertake this intervention when they are supported by specialist services to which they can refer problem drinkers. Thus, specialist services for AUDs should be available and evidence-based nonpharmacological and pharmacological treatments should also be offered to those who have been assessed as likely to benefit. 
Data from a number of recent European projects show that PHC providers considered resources currently allocated for training and delivery of early intervention and treatment not sufficient. The trend has been to move away from lengthy inpatient treatment toward outpatient and community-based one (3).

The current challenge for HS in Europe is how to stick to the values of universality, access to good quality care, equity, and solidarity taking into account the growing challenges (increased costs, population aging, rise of chronic diseases, and multimorbidity leading to growing demand for healthcare, shortages, and uneven distribution of health professionals, health inequalities and inequities in access to healthcare) and bearing in mind the economic crises that are putting endanger the HS's sustainability. EC stresses that HS reforms should focus on (1) strengthen their effectiveness, (2) increase their accessibility, and (3) improve their resilience meaning capable to adapt effectively to changing environments, tackling significant challenges with limited resources.

\section{WIDESPREAD IMPLEMENTATION OF SBI PROGRAMS: WHAT THE EVIDENCE SAYS}

Screening and brief intervention is an effective and cost-effective method for treating subjects with HHAC in PHC. Evidence on the reduction of alcohol consumption is consistent, but its impact on alcohol problems is less clear (7). There are, however, a lot of issues on SBI that need further research: identifying the effective components, their utility among dependent drinkers, assessing fidelity to contents, skills needed to implement SBI, and how professionals may best acquire them. SBI effectiveness in the context of chronic diseases should be tested and demand for alcohol SBI may also be potentiated (8).

Despite its effectiveness and strong research evidence to support its implementation in real-world clinical settings, widespread implementation of SBI has occurred in very few places and it is still unclear if the programs will be sustained. In addition, little is known about the most successful strategies for widespread SBI implementation. Babor et al. (9) found that the effectiveness of different implementation models depends on complex provider and organizational characteristics. Thus, the ability of PHC centers to implement SBI was correlated with prior SBI expertise, centers stability, and number of clinicians trained and negatively correlated with lack of provider time, staff turnover, and competing priorities. Authors suggest that the best option is to combine different methods or multi-faceted strategies (10). In his revision, Williams et al. (11) analyzed under the consolidated framework for implementation research (CFIR) (12) eight implementation programs in nine different countries. He found SBI rates varied a lot and were non-comparable because of the use of different measures, scopes, and durations. He concluded that the use of strategies related to inner setting ("features of the structural, political, and cultural context through which the implementation process proceeds"), outer setting ("economic, political, and social context in which an organization resides"), and process implementation domains could be positively associated with higher screening rates and thus to successful implementation.

So far, institutionalization of SBI, which is sustained and nation-wide extensive SBI activity, has only been reported by programs in Finland, Sweden, and Scotland. Seppänen et al. (13) found an increase over the years and a high percentage of physicians $(78.5 \%)$ offering BI at least occasionally. Among the factors associated with high BI was long experience in $\mathrm{PHC}$ and being a PHC specialist.

Studies in Sweden and Finland have shown that only a minority of the population has been asked about their drinking by $\mathrm{PHC}$ professionals and a minority of risky drinkers has been advised to cut down. Nilsen et al. $(14,15)$ found that only $14-20 \%$ of the overall sample who had visited a physician in the last year recalled having received an alcohol enquiry. Reduced alcohol consumption was reported by $12 \%$ and especially among those who were exposed to a 1-10 min (versus $1 \mathrm{~min}$ ) conversation on alcohol. In the case of Finland, only one-third recalled being asked, and $37 \%$ had been given advice (16).

In England, Kaner (17) claims that national alcohol strategies alone do not result in a wide-scale SBI activity and for that to happen it is needed to create necessary conditions (shaping the policy and commissioning) in which brief interventions become meaningful for those working in clinical practice. Authors also suggest considering system-level factors that influence drinking behavior and policy-level interventions (minimum price per unit for the alcohol sales, restrictions on the density of outlets, etc.) that can reinforce or complement practitioner-level interventions. It was recognized that SBI activity could not occur in public HSys without the prioritization, the support of senior management, or without appropriate resources, including training and support and the definition of integrated care pathways for alcohol prevention and treatment.

Heather (18) also advised that SBI alone, especially with such low levels of people screened and of risky drinkers advice, would be unlikely to result in public health benefits and recommends proposing opportunistic screening to ensure acceptability of SBI programs and to research population-level effects of SBI, especially in combination with other alcohol control measures.

In Scotland (19), where a specific 3-year target (HEAT H4) on brief intervention (149,449 from April 2008 to March 2011 and 61,081 from April 2011 to March 2012) was established to support population-wide implementation, it was proven to be possible to reach it nationally in all priority settings and healthcare staff saw SBI as a worthwhile activity. The reach and impact of the initiative was mixed across Scotland and gaps in coverage were noted, especially in rural and remote areas in relation to age/gender groups who less frequently attended mainstream services.

According to Angus et al. (20), SBI is highly cost-effective for brief intervention at next registration as well as at next general practitioner consultation. Thus, investments in SBI programs not only improve health and save lives but also save HSys money by two levels of action:

- Offering brief interventions to $60 \%$ of the population at risk. This ambitious target would require that every patient who receives primary care services would be offered these interventions, irrespective of the reason for the consultation, and a greater investment in training and supporting primary care providers. 
- Offering early brief interventions to $30 \%$ of the population at risk of HHAC. It can be achieved by putting into place appropriate systems, including provider training, so that every patient who registers with a new primary care provider, receives a health check, consults a provider about particular disease categories (such as hypertension or tuberculosis) or goes to particular types of clinics is offered these interventions. At this level of action, as alternative to standard face-to-face interventions, web-based approaches and self-help guidance could be considered. In this regard, a number of studies are underway to test the effectiveness and the acceptability of this new approach to know if the provision of facilitated access by primary care providers to an alcohol reduction website could significantly increase brief intervention rates by offering a time-saving alternative to face-to-face intervention. These studies include the randomized controlled trial carried out in the Friuli Venezia Giulia Region, Italy (21).

\section{CASE STUDIES PRESENTATION: HSYS FOR BI IN SIX EUROPEAN COUNTRIES}

A literature search showed that only six countries/regions in Europe have been working on the wide implementation of SBI on alcohol, i.e., they have invested intensive and continuous efforts aimed at institutionalizing that programs and their initiatives have been endorsed by national laws, policies, or guidelines. In other countries, such as Slovenia, Czech Republic information is missing. These countries are Finland, Sweden, Scotland, England, Italy, and Catalonia and in Table $\mathbf{1}$ below, a summary of some health resources indicators is given. Sweden is the country that invests more in health and has the highest ratio in nurses and physicians. Finland is the one with the highest ratio in terms of hospital beds. The majority has a shared implementation model, but in Italy and Catalonia regions are fully responsible. Sweden, Finland, and Catalonia have a similar PHC organizational model, whereas in Italy, Scotland, and England PHC is organized as independent contractors. According to the ODHIN assessment report (22), the integration of the management of HHAC in the PHC system (scale $0-10)$ is best in Sweden, followed by Catalonia/Spain, and in secondary health care it is best in Catalonia/Spain, followed by England/UK.

During the last decade all of these countries undertook major reforms of their healthcare systems in the five key identified areas: strengthening health care financing, continuum of care, quality of HSs, linkage with community, and advances in public health. This process has slowed down or even stopped in Catalonia and Italy due to the recession and the cuts in the HSys.

\section{CASE STUDIES ANALYSIS: WHAT HAS BEEN DONE}

Interest in the SBI in the six countries started early, especially in Sweden and Scotland, where the first studies began in the early 80s. All the countries, except Sweden and Scotland, took part in the WHO Collaborative Study (Table 2). Countries joined in different phases, England in Phase II (SBI trial), Italy and Catalonia in Phase III (best ways to achieve wide implementation), and Finland in Phase IV (country-wide SBI implementation strategies).
Phase IV began in 1999 and ended in 2006. While participating countries shared the same objective the specific design and procedures varied among participating countries in order to take account of different country specific needs, factors, and policies and PHC organizational models (23). In Table 2 below, you can find the main characteristics of the implementation that has taken place.

The so-called treatment gap, the proportion of people who actually access treatment out of those who need it, has been reported in the majority of the countries as one of the main motivations to implement SBI. In the study from Wolstenholme et al. (24) across six European countries studied, there was a great variation in the HSys and treatment provision for alcohol use disorders, with the proportion of people in need of treatment who actually access it ranging from 1 in 25 to 1 in 7 . Italy was the country with highest access to treatment $(23.3 \%)$ and England (7.1\%) had one of the lowest. Interestingly, in Sweden the SBI project was launched against a backdrop of increasing alcohol consumption since the country's entry in the EU in 1995 (15). In Scotland, a substantial rise in alcohol-related harm is reported too (25).

As detailed in Table 2, SBI programs share some communalities (AUDIT as screening tool and FRAMES adapted brief intervention), especially among those that participated in the WHO Collaborative project, but its implementation has been adapted to the country HSys organization (PHC settings structure, professionals involved, referral pathways). An important issue is that regardless of the origins, governments have been involved in the SBI program implementation mainly by endorsing national guidelines or policies and providing specific funding for HHAC. As far as we know, only Scotland established a national target and incentivized accordingly. It is not clear, however, if sustainability actions are undertaken in order to maintain results obtained in the different countries.

Italy and Catalonia have based their evaluation more on continuous monitoring strategies than on specific research trials or studies; UK and other countries have followed a much more formal monitoring including a national Audit. Studies on fidelity to national guidelines in such countries do not exist.

Taking into consideration the main conclusions of the Odhin assessment exercise (22), success in the wide implementation of SBI depends on a number of factors: the presence of a formal partnership or coalition to support the process, the integration of the management of the SBI in the health care system, the provision of a formal, mandatory on-going training and medical education on SBI, the existence of written alcohol policies funded SBI research projects (cost-effectiveness, fidelity, quality of advice, evaluation surveys, performance records, etc.), available guidelines and protocols provision of materials and incentive measures, support by specialists services, etc. Furthermore, it is essential that specific activities should be devoted to the dissemination of available sources of knowledge, research results, and information to health care providers together with the provision of materials and tools as well as incentive measures aimed at ensuring that prevention, particularly SBI, is implemented in PHC and supported by specialist services according to a real networking of the available servicers and competencies. 
Table 1 | Health system key characteristics.

\begin{tabular}{|c|c|c|c|c|c|}
\hline & Finland & Sweden & UK & Italy & Spain \\
\hline Population ${ }^{a}$ & $5,413,971$ & $9,519,374$ & $63,705,000$ & $59,539,720$ & $46,146,580$ \\
\hline $\begin{array}{l}\text { Total expenditure on } \\
\text { health/capita, US\$ } \\
\text { purchasing power parity, } \\
2011^{a}\end{array}$ & $2,544.7$ & $3,203.6$ & $2,821.1$ & $2,344.5$ & $2,244.2$ \\
\hline Health resources density & 10.45 (Nurses) & 11.09 (Nurses) & 8.21 (Nurses) & (Nurses) & 5.24 (Nurses) \\
\hline per 1000 population & 2.72 (Physicians) - 2008 & 3.92 (Physicians) & 2.75 (Physicians) & 3.85 (Physicians) & 3.82 (Physicians) \\
\hline (head counts) $^{a}$ & 5.3 (Hospital beds) & 2.62 (Hospital beds) & 2.81 (Hospital beds) & 3.4 (Hospital beds) & 2.97 (Hospital beds) \\
\hline Type & Compulsory tax-based & Compulsory tax-based & National taxation & General taxation & Tax-based \\
\hline Planning/implementation & $\begin{array}{l}\text { National planning, local } \\
\text { (municipalities) } \\
\text { implementation }\end{array}$ & $\begin{array}{l}\text { Central state, regions } \\
\text { and local health } \\
\text { authorities (shared } \\
\text { responsibility) }\end{array}$ & $\begin{array}{l}\text { Country (England, NI, } \\
\text { Scotland, and Wales) } \\
\text { deliver services } \\
\text { through public } \\
\text { providers }\end{array}$ & $\begin{array}{l}\text { Central state, regions, } \\
\text { and local health } \\
\text { authorities (shared } \\
\text { responsibility) }\end{array}$ & $\begin{array}{l}\text { Central state defines } \\
\text { minimum } \\
\text { requirements and } \\
\text { coordinates, } \\
\text { autonomous } \\
\text { communities are fully } \\
\text { responsible }\end{array}$ \\
\hline Health care provision & $\begin{array}{l}\text { PHC centers are } \\
\text { multidisciplinary and } \\
\text { public owned and provide } \\
\text { (primary care, preventive } \\
\text { care and public health } \\
\text { services) }\end{array}$ & $\begin{array}{l}\text { PHC services deliver } \\
\text { both basic curative } \\
\text { care and preventive } \\
\text { services through local } \\
\text { health centers }\end{array}$ & $\begin{array}{l}\text { PHC is provided by } \\
\text { GPs in group practices } \\
\text { (three per practice) }\end{array}$ & $\begin{array}{l}\text { GPs and pediatricians } \\
\text { working as } \\
\text { independent } \\
\text { contractors provide } \\
\text { primary health care }\end{array}$ & $\begin{array}{l}\text { PHC centers are } \\
\text { multidisciplinary and } \\
\text { public owned and } \\
\text { provide primary and } \\
\text { preventive care }\end{array}$ \\
\hline $\begin{array}{l}\text { Self-declared unmet } \\
\text { needs for medical } \\
\text { examination (EU } \\
\text { rate }=3.4 \%)^{b}\end{array}$ & Above & Below & Below & Above & Below \\
\hline $\begin{array}{l}\text { Integration of the } \\
\text { management of } \\
\text { hazardous and harmful } \\
\text { alcohol consumption in } \\
\text { the primary and } \\
\text { secondary health care } \\
\text { system (scale 0-10)c }\end{array}$ & $5 / 5$ & $10 / 4$ & 5/6 (England only) & $5 / 4$ & $8 / 8$ \\
\hline
\end{tabular}

${ }^{a}$ OECD Health Statistics, 2013 - http://stats.oecd.org/index.aspx?DataSetCode=SHA

${ }^{b}$ Eurostat statistics on income and living conditions, 2012.

${ }^{c}$ ODHIN assessment tool - report, 2013 - http://www.odhinproject.eu/project-structure/wp6. html

PROPOSAL FOR THE FUTURE: THE WHO-EURO STRATEGY ON HSys FOR BI

Alcohol, in contrast to other behaviors and lifestyles poses important challenges to the HSys, mainly because of moral prejudices existing in our society, to the fact that alcohol consumption is culturally and socially determined and to the fact that there in some cases it is associated to brain malfunctioning or a brain disease. This together with the barriers in every day practice to sustaining commitment such of lack of time, lack of training and resources, a belief that patients will not take advice to change drinking behavior and a fear of offending patients by discussing alcohol $(26,27)$ has resulted in HSys oriented toward an individualized, passive, and an illness-centered model of health care in which SBI implementation is utopic.

Coming to this point, it is clear that unless the HSys adopts more holistic and patient-centered implementation models, the SBI implementation on HHAC will not be achieved and sustained despite all the research and efforts done. In this direction, we would like to emphasize the relevance of the contributions made by:

\section{TBLISI RESOLUTION}

Behavior Change strategies and health: the role of HSys (6) that acknowledges the fact that behavior-related risk factors have become the leading causes of morbidity and mortality and that 


\begin{tabular}{|c|c|c|c|c|c|c|}
\hline & Finland $^{a}$ & Sweden & Scotland ${ }^{b}$ & England & Italy & Catalonia/Spain \\
\hline Origin & $\begin{array}{l}\text { Late 90s. Phase IV of the } \\
\text { WHO Collaborative } \\
\text { Project }^{\mathrm{C}} \text {. PHC and } \\
\text { occupational health }\end{array}$ & $\begin{array}{l}\text { Early 80s Malmö study. } \\
\text { Risky drinking Project } \\
\text { (2004-2010) in PHC, } \\
\text { maternity and occupational } \\
\text { health care }\end{array}$ & $\begin{array}{l}\text { Early 80s DRAM Study. } \\
\text { Scotland performance } \\
\text { management target } \\
\text { (H4:Heat target) }{ }^{d}\end{array}$ & $\begin{array}{l}\text { Late 80s. Phase II of the } \\
\text { WHO collaborative project. } \\
\text { SIPS trials (PHC, } \\
\text { emergency departments } \\
\text { and criminal justice } \\
\text { settings }\end{array}$ & $\begin{array}{l}\text { Early 90s. Phase III strand I } \\
\text { of the WHO Collaborative } \\
\text { Project }\end{array}$ & $\begin{array}{l}\text { Mid 90s. Phase III-strand } \\
\text { III of the WHO } \\
\text { Collaborative Project. } \\
\text { Phase IV on } \\
\text { implementation started in } \\
2002\end{array}$ \\
\hline $\begin{array}{l}\text { National } \\
\text { guidelines }\end{array}$ & $\begin{array}{l}\text { Yes. Part of other clinical } \\
\text { care guidelines }\end{array}$ & $\begin{array}{l}\text { Yes. Stand alone guidelines } \\
\text { (GP) }\end{array}$ & $\begin{array}{l}\text { Yes. Stand alone guidelines } \\
\text { (GP and nurses). The } \\
\text { management of harmful } \\
\text { drinking and alcohol } \\
\text { dependence in primary }_{\text {care }^{f}}\end{array}$ & $\begin{array}{l}\text { Yes. Stand alone guidelines } \\
\text { (GP and nurses) NICE } \\
\text { guidance on the prevention } \\
\text { of hazardous and harmful } \\
\text { drinking plus a Nationally } \\
\text { Directed Enhanced service }\end{array}$ & $\begin{array}{l}\text { Yes. Stand alone guidelines } \\
\text { (GP). PHEPA }{ }^{e} \text { adapted at } \\
\text { national level }\end{array}$ & $\begin{array}{l}\text { Yes. Stand alone guidelines } \\
\text { (GP and nurses). PHEPA } \\
\text { adapted at national level } \\
\text { and PAPPS }\end{array}$ \\
\hline Professionals & $\begin{array}{l}\text { Both GP }(1,000) \text { and } \\
\text { nurses }(2,000)\end{array}$ & $\begin{array}{l}\text { Both GP, residents in } \\
\text { family medicine and } \\
\text { district nurses }\end{array}$ & $\begin{array}{l}\text { GP and other PHC } \\
\text { professionals (practice and } \\
\text { community nurses and } \\
\text { health visitors) }\end{array}$ & Both GP and nurses & $\begin{array}{l}\text { GPs, psychiatrists, family } \\
\text { advice bureau from PHC; } \\
\text { psychologists, professional } \\
\text { from the Ser.T.S. and } \\
\text { workplace }\end{array}$ & Both GP and nurses \\
\hline Screening & $\begin{array}{l}\text { Opportunistic screening } \\
\text { with AUDIT }\end{array}$ & AUDIT & $\begin{array}{l}\text { Clinical presentations and } \\
\text { new registrations. } \\
\text { Abbreviated forms of } \\
\text { AUDIT (e.g., FAST), or } \\
\text { CAGE plus two } \\
\text { consumption questions, } \\
\text { should be used in primary } \\
\text { care when alcohol is a } \\
\text { possible contributory } \\
\text { factor }\end{array}$ & $\begin{array}{l}\text { Targeted screening with } \\
\text { AUDIT and AUDIT-C }\end{array}$ & $\begin{array}{l}\text { Targeted screening with } \\
\text { AUDIT and AUDIT-C on a } \\
\text { voluntary basis }\end{array}$ & $\begin{array}{l}\text { Universal with existing } \\
\text { tools (quantity and } \\
\text { frequency) in medical } \\
\text { records and AUDIT } \\
\text { (voluntary) }\end{array}$ \\
\hline Brief intervention & FRAMES adapted BI & $\begin{array}{l}\text { Feedback and BI. } \\
\text { MI-principles }\end{array}$ & $\begin{array}{l}\text { FRAMES adapted BI } \\
\text { (10 min) }\end{array}$ & $\begin{array}{l}\text { Simple structured advice } \\
\text { and brief behavioral } \\
\text { counseling }\end{array}$ & $\begin{array}{l}\text { Based on PHEPA } \\
\text { guidelines (FRAMES } \\
\text { adapted BI) }\end{array}$ & FRAMES adapted BI \\
\hline Training ${ }^{g}$ & $\begin{array}{l}\text { Both vocational and } \\
\text { continuing medical } \\
\text { education (GP and nurses) }\end{array}$ & $\begin{array}{l}\text { Only vocational training } \\
\text { (GP). During the project: } \\
\text { half and whole day } \\
\text { information seminars and } \\
\text { network meetings }\end{array}$ & $\begin{array}{l}\text { Training of trainers (100). } \\
\text { NHS health Scotland } \\
\text { trained over } 3200 \\
\text { practitioners (Training } \\
\text { manual, DVD and a } \\
\text { national competency }\end{array}$ & $\begin{array}{l}\text { Partially available } \\
\text { vocational training and } \\
\text { continuing medical } \\
\text { education (GP and nurses). } \\
\text { During the project: training } \\
\text { of trainers (How much is } \\
\text { too much package) }\end{array}$ & $\begin{array}{l}\text { Only vocational training } \\
\text { (GP). During the project: } \\
\text { training of trainers (PHEPA } \\
\text { training manual) and } \\
\text { continuing medical } \\
\text { education (ECM) }\end{array}$ & $\begin{array}{l}\text { Both vocational and } \\
\text { continuing medical } \\
\text { education (GP and nurses) } \\
\text { Training by peers in the } \\
\text { PHC (Beveu Menys } \\
\text { package) }\end{array}$ \\
\hline
\end{tabular}


Table 2 | Continued

\begin{tabular}{|c|c|}
\hline & Finland $^{a}$ \\
\hline $\begin{array}{l}\text { Incentives or part } \\
\text { of normal salary }\end{array}$ & Part of normal salary \\
\hline $\begin{array}{l}\text { Support for } \\
\text { managing SDA in } \\
\text { specialized } \\
\text { treatment } \\
\text { facilities }\end{array}$ & Yes \\
\hline $\begin{array}{l}\text { Monitoring and } \\
\text { evaluation }\end{array}$ & $\begin{array}{l}\text { Pre-post. Mailed } \\
\text { questionnaire to all PHC } \\
\text { physicians (2002-2007). } \\
\text { Face-to-face interviews } \\
\text { (2008) (self-report } \\
\text { measures). } 25 \% \text { of Finnish } \\
\text { population but concerted } \\
\text { attempt to cover the whole } \\
\text { country }\end{array}$ \\
\hline
\end{tabular}

Sweden

Scotland

England

Italy

Catalonia/Spain

Incentives

Incentives

Part of normal salary

Part of normal salary

Small incentives

funding for

Yes

Yes. Access to relapse

prevention treatments

Yes. Evidence-based care

pathway for different levels

of alcohol-related risk harm

and dependence

services for

$\mathrm{HHAC}$

\section{Specific national \\ Yes. Finnish alcohol}

policy

program (2004-2007)
Yes

Pre-post.

Telephone-administered

questionnaire to general

population (2006-2009)

(self-report measures)
Government initiative

Health service target of

delivering $149,449 \mathrm{BI}$

2008/2009-2010/201
National audit office report. Not on SBI

annual care quality

and reach

Yes

Yes. Cooperation with 21

county councils.

Supervision by the

professional organizations,

local authorities, Hospitals,

etc commission report

implementation but on

alcohol consumption,

mortality, attributable

hospital discharges and on

public specialist alcohol

service activities (125/2001

law on alcohol

Yes

National alcohol strategies

Frame law on alcohol

125/2001

National alcohol and health

plan (PNAS)

National prevention plan

(PNP)

National health plan (PSN)

Yes. National Observatory

on Alcohol-CNESPS,

Istituto Superiore di Sanità

(with funding from the

$\mathrm{MoH}$ and the Presidency

of the Council of the

Ministries, Dept of

antidrugs policies
Yes. Strategy on

coordination between PHC and specialist services for

alcohol dependence

Annual screening rates

(contract with $\mathrm{PHC}$

providers

management of

$\mathrm{HHAC}$

No but included in the health Plan (2012-2016) prevention Yes. Program on Substance Abuse of the time nurse and half time providers and Catalan Society of Family and Community Physicians and Nurses 
they cannot be seen in isolation, as they mostly are inextricably connected with the social determinants of health.

\section{TALLINN CHARTER}

Health system for health and wealth (6) that stresses that effective primary care is essential to provide a platform for the interface of HSs with communities and families and for intersectoral cooperation and health promotion that HSys should integrate targeted disease-specific programs into existing structures and services and that HSys need to ensure a holistic approach to services, involving health promotion, disease prevention, and integrated disease management programs, as well as coordination among a variety of providers, institutions, and settings, irrespective of whether these are in the private or public sector and including primary care, acute, and extended care facilities and people's homes, among others.

Thus, talking specifically about the management of HHAC, the Tblisi resolution tells us that complex factors influencing alcohol behavior change should be taken into account in order to design proper interventions (see Table 3).

All the factors listed above are applicable to alcohol behavior change and to the design of alcohol interventions. The behavioral change model acknowledges the important role that, for example, the physical and social environments, the social relationships, and the social norms play on the alcohol consumption and as a result of this, alerts on the limit to a person's capacity to change, if the environment militates against the desired change; and the importance to create conditions and incentives for change, in addition to giving messages and advice and building personal skills. This model also stresses that some people are just physiologically incapable of drinking moderately and that in such cases actions to empower (29), to increase self-esteem (30) and resilience (31) of the harmful drinkers should also be implemented to increase effectiveness. Thus, behavior change could benefit from information, education, and capacity building interventions, at community and, especially, at individual level.

In addition to that, according to the Tallinn charter, it is clear that the implementation of SBI in PHC alone would not produce the effect we are aiming for.

From the model proposed (see Table 4), it is clear that in order to introduce such individually oriented strategies by $\mathrm{PHC}$ it is essential to embed them into settings and systems oriented strategies such as health promotion approaches and community and population strategies such as mass media campaigns regulation and legislation and capacity building.

Taking all this into account, the following considerations could be made.

- From a Public Health point of view, to increase the effectiveness of any alcohol risk reduction all these aspects need to be taken into consideration and the respective stakeholders need to be involved in a wide, holistic, intersectoral approach. Social and HSs, culture and education, pharma industry, local authorities, private sector, general population representatives, and the economic sector are only some of the participants that need to be involved. 
Table 3 | Common factors influencing behavior change and their implications for intervention design [adapted from WHO European Ministerial Conference on Health Systems (28)].

\section{Factors}

A desire for change must be present in the audience

Participatory involvement leads to greater behavioral change effects

People are often motivated to do the "right thing" for the community as well as for themselves and their families

Social relationships, social support, and social norms have a strong and persistent influence on behavior

Change is usually a process not an event

Psychological factors, beliefs, and values influence how people behave

People can be "locked into" patterns of behavior and need practical help to break them

Change is more likely if an undesired behavior is not part of an individual's life situation coping strategy

People's behavior is influenced by their physical and social environments

People's perception of their vulnerability to a risk and of its severity is key to understanding behavior

Perceptions of the effectiveness of the recommended behavior change are key factors affecting decisions to act

The more beneficial or rewarding an experience, the more likely it is to be repeated

People are loss-averse: they will put more effort into retaining what they have than into acquiring new assets

People often rely on mental short cuts and trial-and-error to make decisions, rather than on rational computation

\section{Design implication}

There is a need both to create a demand for positive change and to create the conditions to enable people to make positive choices

Interactive engagement strategies and the development of coalition approaches to change should be part of all behavior change interventions

Programs should encourage and incentivize socially responsible behavior and penalize behaviors that are not socially responsible

Incorporating peer and family support strategies into individual risk change programs increases likely success

Programs should be sustained over time and tailored to the needs of different groups

Programs need to address values and beliefs, as well as information and knowledge acquisition

Policy and services need to be designed to meet the specific needs of different communities, in order to help them change engrained habits

Create incentives, offer practical support for change, and give positive reinforcement. Provide alternative forms of support and reinforcement to aid behavior change

There is a limit to a person's capacity to change, if the environment militates against the desired change; conditions and incentives for change must therefore be created, in addition to giving messages and advice and building personal skills

There is a need to develop individual and community understanding of risk and vulnerability in relation to major threats

Programs should seek to ensure that people understand the scale of the rewards associated with positive behavior change

Reinforcing and incentivizing positive behavior in the short term should be part of any change program

Programs should emphasize the advantages of positive behaviors that enable a continuation of immediate benefits, rather than long-term gains

Programs should develop a deep understanding about what will motivate people to change and how they perceive specific issues
- From an individual point of view, primary healthcare and general practitioners (GPs), in particular, need to participate because they can take care of all those issues and work for behavioral change in an effective way $(32,33)$. They provide lifelong, continuing, co-ordinated, and community oriented care to their patients and are widely seen by them as their most trusted health providers. They are also recognized as being the gatekeepers in many European HSys and they are the only health professionals that have the formal role and possibility to recover information on every health determinant, educate, and provide support to their patients. Genetics, mental health, family situation, culture, religious beliefs, and socio-economic positions can be easily accessed by these experts assuring thus a holistic approach. In their everyday work, GPs should know that increasing awareness and knowledge is essential for behavioral change but they are seldom sufficient to promote a sustainable modification in health behaviors. The ability to change is also influenced by each citizen's values, attitudes and norms, self-perception and capacity for sustaining the change, expectations of success and failure before embarking on a change program.

- Apart from increasing health literacy and managing health issues, we need to influence individual attitudes and the level of confidence, which are more bound to health determinants such as culture, social models, economic, and working conditions. Individual health needs should be addressed and 
Table 4 | Components of a comprehensive approach to health behavior change [adapted from WHO European Ministerial Conference on Health Systems (28)].

\section{Community and whole of population strategies}

Legislation and regulation

Environmental Change (footpaths, cycleways, lighting)

Community partnerships

Community capacity building

\section{Settings and systems oriented strategies}

Setting intervention:

workplaces

Social support, e.g., walking group Telephone counseling

Individually oriented strategies

Personal goal-setting
Setting intervention:

educational institutions

Self-monitoring, e.g., daily-diary
Existing community structures and leadership

Setting intervention:

primary health care

Signs/cues at points of

decision-making

1:1 or group counseling
Mass media campaigns

Culturally and behaviorally tailored programs

Setting intervention:

home and family

Internet also individual resources, in a non-medical, positive, health promotion approach.

\section{CONCLUSION}

This review contextualizes the importance of the implementation of SBI in the context of effective alcohol policies, summarizes the main effectiveness and cost-effectiveness evidence, and describes the major accomplishments achieved with nation-wide SBI implementation programs in Europe. This review also provides the means to think of different approaches if more effective AUDs strategies are to be proposed at European level. Social, economic, and health promotion points of view are also presented as important aspects to be explored for the good outcome of any AUDs strategy.

Major and diverse issues were identified in this review:

- Implementation is still not Country- and Europe-wide. Pilot experiences should be generalized. The recent trial results strongly reinforce the already expressed suspicion that it is extremely difficult to get health professionals to deliver SBI; The ODHIN assessment tool shows that, in 2012, EIBI was still not the norm in daily consultation in PHC and that more resources are needed to overcome the main obstacles.

- Enduring behavior change and improvements on biochemical and biometric measures are unlikely after a single routine consultation with a clinician trained in behavior change counseling, without additional intervention.

- A tailored, implementation multi-faceted program aimed at improving general practitioner management of alcohol consumption showed little evidence to support the use of such an intensive implementation program to improve the management of harmful and hazardous alcohol consumption in primary care.

- Despite the efforts made toward the country-wide implementation of SBI programs, comparisons are difficult, not only due to the different context and implementation strategies used but also by the diversity of the outcome and output indicators used. Little can be said about what works, what does not and in what contexts.
- As stated by many authors $(11,34)$, further evaluation of all the programs under a common evaluation framework like the reach, effectiveness, adoption, implementation, and maintenance (REAIM) or the CFIR that go beyond the standard models of technology diffusion would be essential in order to extract more structured ideas on the implementation needs. Authors $(8,35)$ suggest that new modes of delivery such as via internet may help to surmount some of the challenges of wide dissemination, such as strains on expertise, time, and resources but still more research has to be done on its efficacy and effectiveness. In addition to that, in order to achieve a population-wide dissemination it is essential to involve other health and social settings and actors, thus, expanding SBI evidence is essential. In this sense, initiatives such as the "BISTAIRS project" - will provide useful information on how to foster the implementation of SBI for AUDs in a variety of settings (PHC, workplace HSs, emergency care, and social services) and extending best practices in Europe $(36,37)$.

- Implementing SBI through a PHC system approach is important because addressing risky drinking is a complex issue, involving different actors from different parts of the society. Families, local communities, and work environments are the usual settings where those risks are generated and PHC is the right place to understand the conditions that bring people to adopt unhealthy lifestyles.

Taking into account all these elements listed above, leads inevitable to the need to reframe SBI. The challenge is how to do it without impacting on its cost-effectiveness and practicability in PHC to reduce alcohol health risks $(20,38)$. Some suggestions will be:

- To broaden it to a brief motivational intervention, which could allow professionals to understand and evaluate individual health determinants and self-esteem and to determine people's motivations to change by addressing patient's importance and confidence to change and help them to understand the individual conditions underlying their risky drinking. 
- To strengthen the links with territorial services as an essential way to provide structural support, when needed.

- To broaden brief interventions to allow a more traditional, pharmacological treatment, more in line with professional's (especially GPs) attitudes and views.

- To abandon simplistic and potentially unhelpful positions of putting on each individual patient the sole responsibility and decision to adopt healthier behaviors to avoid ill health.

- To integrate peer and family support strategies into individual risk modification in order to increase the SBI success (39).

- To propose alcohol SBI within the broader issues of all lifestyles and within the context of a global cardiovascular and cancer risk reduction. Asking about alcohol drinking, food intake or tobacco smoking, just like asking about blood pressure, can be an easy step forward to increase effectiveness.

- To integrate brief interventions with on-going practical support for structural changes performed by other actors (social services, community networks, psychologists, psychiatrists, etc.) could ease the work of primary healthcare and allow a better management of AUDs.

- To take advantage of new information and communications technologies (ICT) to help addressing the problem and enabling patients and health care providers to work as co-producers of health. Without abandoning completely the traditional face-toface engagement, there is mounting evidence of the effectiveness of delivering aspects of healthcare using the Internet and mobile phone applications for the promotion of healthier lifestyles (smoking cessation, healthier drinking choices, and weight loss) $(40,41)$. Work is also underway on the development of digital technologies to enable patients with long-term conditions such as AUDs, obesity, and chronic obstructive airways disease to engage more actively in the management of their own health and trials are being undertaken to evaluate the potential of these applications to deliver benefits in relation to patient satisfaction and wellbeing as well as clinical outcomes (21).

- To work closely in connection with patients and the public as well as different stakeholders (medical and social, the pharmaceutical industry, public health authorities, ICT and m-health actors, health economists, health insurers) to understand people's attitudes and motivations, as well as barriers to change, perceived or real, in a real community holistic approach, to address health determinants and explore new, co-produced health models. Be involved in alcohol risk management considering the need to reduce stigma by including alcohol in usual care, with other lifestyle related risks and in the broader question of cardiovascular risk management.

- To create more appealing specialist services to help reducing stigma associated to AUD.

- The fact that it is difficult to effectively implement and maintain SBI strategies should bring policy makers to explore new possibilities, linking different stakeholders with different approaches, and trying new methodologies, including the provision of appropriate training, incentives, and implementation strategies.

In summary, alcohol use is a complex issue, at least as much so as hypertension or diabetes. Thus, thinking that a single intervention, even if effective, such as SBI, could solve the problem is, to our point of view, naïve, and restrictive. Future strategies should aim at broadening the perspective from an individual and a HSys point of view. HSs are important in addressing AUDs but only if individual tailored strategies are proposed, taking into consideration all the complexity of human being and his environment in a Health System approach (42).

\section{REFERENCES}

1. Martinotti G, Lupi M, Acciavatti T, Cinosi E, Santacroce R, Signorelli MS, et al. Novel psychoactive substances in young adults with and without psychiatric comorbidities. Biomed Res Int (2014) 2014:815424. doi:10.1155/2014/815424

2. Farren CK, Hill KP, Weiss RD. Bipolar disorder and alcohol use disorder: a review. Curr Psychiatry Rep (2012) 14(6):659-66. doi:10.1007/s11920-0120320-9

3. WHO Regional Office for Europe. European Action Plan to Reduce the Harmful Use of Alcohol 2012-2020 (2011). Available from: http://www.euro.who.int/_ data/assets/pdf_file/0006/147732/RC61_wd13E_Alcohol_111372_ver2012.pdf

4. Institute of Alcohol Studies-IAS. IAS Fact Sheet (2013). Available from: http:// www.ias.org.uk/uploads/pdf/Factsheets/Health\%20Service $\% 20$ Response $\% 20 \mathrm{~F}$ S\%20May\%202013.pdf

5. WHO. Global Strategy to Reduce the Harmful Use of Alcohol. Geneva: HS Response (2010).

6. WHO. Toolkit on Monitoring HSys Strengthening (2008). Available from: http://www.who.int/healthinfo/statistics/toolkit_hss/EN_PDF_Toolkit_ HSS_ServiceDelivery.pdf?ua $=1$

7. Kaner EF, Dickinson HO, Beyer F, Pienaar F, Schlesinger C, Campbell F, et al. The effectiveness of brief alcohol interventions in primary care settings: a systematic review. Drug Alcohol Rev (2009) 28:301-23. doi:10.1111/j.1465-3362. 2009.00071.x

8. McCambridge J, Rollnick S. Should brief interventions in primary care address alcohol problems more strongly? Addiction (2014) 109:1054-8. doi:10.1111/add. 12388

9. Babor TF, Higgins-Biddle J, Hauser D, Higgins P, Burleson J. Alcohol screening and brief interventions in primary care settings: implementation models and predictors. J Stud Alcohol (2005) 66(3):361-8.

10. Nilsen P, Aalto M, Bendtsen P, Seppä K. Effectiveness of strategies to implement brief alcohol interventions in primary healthcare. A systematic review. Scand J Prim Health Care (2006) 24:5-15. doi:10.1080/02813430500475282

11. Williams EC, Jonhson L, Lapham GT, Chew L, Fletcher GS, Weppner WG, et al. Strategies to implement alcohol screening and brief intervention in primary care settings: a structured literature review. Psychol Addict Behav (2011) 25(2):206-14. doi:10.1037/a0022102

12. Damschroeder LJ, Aron DC, Keith RE, Kirsch SR, Alexander JA, Lowery JC. Fostering implementation of HSs research findings into practice: a consolidated framework for advancing implementation science. Implement Sci (2009) 4:50. doi:10.1186/1748-5908-4-50

13. Seppänen KK, Aalto M, Seppä K. Institutionalization of brief alcohol intervention in primary health care - the Finnish case. Alcohol Clin Exp Res (2012) 36(8):1456-61. doi:10.1111/j.1530-0277.2012.01755.x

14. Nilsen P, Holmquist M. Alcohol Issues in Daily Healthcare. The risk Drinking Project: Background, Strategy and Results. Stockholm: Swedish National Institute of Public Health (2010).

15. Nilsen P, McCambridge J, Karlsson N, Bendtsen P. Brief interventions in routine health care: a population-based study of conversations about alcohol in Sweden. Addiction (2011) 106:1748-56. doi:10.1111/j.1360-0443.2011.03476.x

16. Makela P, Havio M, Seppä K. Alcohol-related discussions in health care: a population view. Addiction (2011) 106:1239-48. doi:10.1111/j.1360-0443.2010. 03356.x

17. Kaner E. NICE work if you can get it: development of national guidance incorporating screening and brief intervention to prevent hazardous and harmful drinking in England. Drug Alcohol Rev (2010) 29:589-95. doi:10.1111/j.14653362.2010.00236.x

18. Heather N. Can screening and brief interventions lead to population-level reductions in alcohol related harm? Adicct Sci Clin Pract (2012) 7:2015 doi:10.1186/1940-0640-7-15

19. Parkes T, Atherston I, Evans J et al. Edinburgh: NHS Health Scotland, 2011. Available from: http://findings.org.uk/docs/Parkes_T_2_findings.pdf 
20. Angus C, Scafato E, Ghirini S, Torbica A, Ferre F, Struzzo P, et al. Costeffectiveness of a program of screening and brief interventions in primary care in Italy. BMC Fam Pract (2014) 15:26. doi:10.1186/1471-2296-15-26

21. Struzzo P, Scafato E, McGregor R, Della Vedova R, Verbano L, Lygidakis C, et al. A randomised controlled non-inferiority trial of primary care-based facilitated access to an alcohol reduction website (EFAR-FVG): the study protocol. BMJ Open (2013) 3(2):ii:e002304. doi:10.1136/bmjopen-2012-002304

22. Gandin C, Scafato E. ODHIN Assessment Tool Report. A Description of the Availablee Services for the Management of Hazardous and Harmful Alcohol Consumption (2013). Available from: http://www.odhinproject.eu/resources/documents/ cat_view/3-odhin-project-documents/6-technical-reports-and-deliverables. html

23. Heather N. Developing, evaluating and implementing alcohol brief interventions in Europe. Drug Alcohol Rev (2011) 30:138-47. doi:10.1111/j.1465-3362. 2010.00267.x

24. Wolstenholme A, Drummond C, Deluca P, Davey Z, Elzerbi C, Gual A et al. Report on the Mapping of European Need and Service Provision for Early Diagnosis and Treatment of Alcohol Use Disorders (2013). Available from: http://amphoraproject.net/w2box/data/Deliverables/AMPHORA_WP6_ D2.5.pdf

25. Graham LJ, Mackinnon D. Grasping the thistle: the role of alcohol brief interventions in Scottish alcohol policy. Drug Alcohol Rev (2010) 29(6):603-7. doi:10.1111/j.1465-3362.2010.00245.x

26. Wilson $\mathrm{G}$, Lock $\mathrm{C}$, Heather $\mathrm{N}$, et al. Intervention against excessive alcohol consumption in primary health care: a survey of GPs' attitudes and practices in England ten years on. Alcohol Alcohol (2011) 46(5):570-7. doi:10.1093/alcalc/ agr067

27. Aira M, Kauhanen J, Larivaara P, Rautio P. Factors influencing inquiry about patients' alcohol consumption by primary health care physicians: qualitative semi-structured interview study. Fam Pract (2003) 20:270-5. doi:10.1093/ fampra/cmg307

28. WHO European Ministerial Conference on Health Systems. The Tallinn Charter: Health Systems for Health and Wealth. Tallin: WHO Europe, Copenhagen (2008). p. 25-7.

29. Koelen MA, Lindström B. Making healthy choices easy choices: the role of empowerment. Eur J Clin Nutr (2005) 59(Suppl 1):S10-6. doi:10.1038/sj.ejcn. 1602168

30. Kuntsche E, Rehm J, Gmel G. Characteristics of binge drinkers in Europe. Soc Sci Med (2004) 59(1):113-27. doi:10.1016/j.socscimed.2003.10.009

31. Wong MM, Nigg JT, Zucker RA, Puttler LI, Fitzgerald HE, Jester JM, et al. Behavioral control and resiliency in the onset of alcohol and illicit drug use: a prospective study from preschool to adolescence. Child Dev (2006) 77:1016-33. doi:10.1111/j.1467-8624.2006.00916.x

32. Lock C, Kaner E. A Survey of General Practitioners' Knowledge, Attitudes and Practices Regarding the Prevention and Management of Alcohol-Related Problems: An Update of a World Health Organisation Survey Ten Years on. London: Alcohol Education and Research Council (2009).
33. Anderson P. Managing alcohol problems in general practice. $\mathrm{Br}$ Med J (1985) 290:1873-5. doi:10.1136/bmj.290.6485.1873

34. Glasgow RE, Vogt TM, Boles SM. Evaluating the public health impact of health promotion interventions: the RE-AIM framework. Am J Public Health (1999) 89:1322-7. doi:10.2105/AJPH.89.9.1322

35. Moyer A, Finney JW. Brief interventions for alcohol problems. factors to facilitate implementation. Alcohol Res Health (2004-2005) 28(1):44-50.

36. O’Donnell A, Anderson P, Newbury-Birch D, Schulte B, Schmidt C, Reimer J, et al. The impact of brief alcohol interventions in primary heathcare: a systematic review of reviews. Alcohol Alcohol (2013):1-13. doi:10.1093/alcalc/ agt 170

37. Schmidt C. Effectiveness of Brief Interventions in Primary Health Care, Emergency Care, Workplace, Health and Social Services (2013). Available from: http://www.bistairs.eu/material/BISTAIRS_WP4_evidence_report.pdf

38. Raistrick D, Heather N, Godfrey C. Review of the Effectiveness of Treatment for Alcohol Problems. London: NHS: National Treatment Agency for Substance Misuse (2006)

39. Dahlgren G, Whitehead M. European Strategies for Tackling Social Inequities in Health: Levelling up Part 2. Copenhagen: World Health Organization (2006).

40. Harris SK, Csémy L, Sherritt L, Starostova O, Van Hook S, Johnson J, et al. Computer-facilitated substance use screening and brief advice for teens in primary care: an international trial. Pediatrics (2012) 129(6):1072-82. doi:10.1542/ peds.2011-1624

41. Wallace P, Murray E, McCambridge J, Khadjesari Z, White IR, Thompson SG, et al. On-line randomized controlled trial of an Internet based psychologically enhanced intervention for people with hazardous alcohol consumption. PLoS One (2011) 6:e14740. doi:10.1371/journal.pone.0014740

42. WHO. EUR/RC58/R8. Euro Copenhagen: WHO (2008). 82183 p.

Conflict of Interest Statement: The authors declare that the research was conducted in the absence of any commercial or financial relationships that could be construed as a potential conflict of interest.

Received: 30 June 2014; accepted: 28 October 2014; published online: 11 November 2014.

Citation: Colom J, Scafato E, Segura L, Gandin C and Struzzo P (2014) Brief interventions implementation on alcohol from the European health systems perspective. Front. Psychiatry 5:161. doi: 10.3389/fpsyt.2014.00161

This article was submitted to Addictive Disorders and Behavioral Dyscontrol, a section of the journal Frontiers in Psychiatry.

Copyright (c) 2014 Colom, Scafato, Segura, Gandin and Struzzo. This is an open-access article distributed under the terms of the Creative Commons Attribution License (CC $B Y)$. The use, distribution or reproduction in other forums is permitted, provided the original author(s) or licensor are credited and that the original publication in this journal is cited, in accordance with accepted academic practice. No use, distribution or reproduction is permitted which does not comply with these terms. 